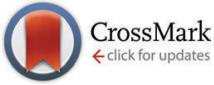

Cite this: J. Mater. Chem. C, 2016, 4,201

Received 14th October 2015, Accepted 24th November 2015

DOI: $10.1039 / \mathrm{c} 5 \mathrm{tc} 03333 \mathrm{k}$

www.rsc.org/MaterialsC

\section{The structures and magnetic properties of $\mathrm{Fe}_{x} \mathrm{Co}_{1-x} \mathrm{Sb}_{2} \mathrm{O}_{4}$ and $\mathrm{Mn}_{x} \mathrm{Co}_{1-x} \mathrm{Sb}_{2} \mathrm{O}_{4}, 0 \leq x \leq 1 \dagger$}

\begin{abstract}
James Cumby, $\$ \S$ Benjamin P. de Laune $\S$ and Colin Greaves*
$\mathrm{Mn}_{x} \mathrm{CO}_{1-x} \mathrm{Sb}_{2} \mathrm{O}_{4}$ and $\mathrm{Fe}_{x} \mathrm{CO}_{1-x} \mathrm{Sb}_{2} \mathrm{O}_{4}$ have been synthesised for $0 \leq x \leq 1$ and their structures and magnetic properties examined. For all compounds, neutron powder diffraction (NPD) data reveal a canted AFM structure that changes gradually from C-type $(x=0)$ to A-type $(x=1)$. This transition corresponds to a gradual rotation of the moments through $90^{\circ}$, from $\pm[001]$ to $\pm[100]$. It is primarily caused by a change in the relative magnitudes of the three types of magnetic exchange that exist between cations. Within a given chain, direct exchange promotes an antiferromagnetic ground state for the two cations and $90^{\circ}$ superexchange that favours ferromagnetic order. Between chains, antiferromagnetic order is preferred. However, the observed magnetic moments (from NPD) are significantly lower than expected except for the end-members of the series; this suggests that incomplete magnetic order is present. Magnetic susceptibility data also suggest complex magnetic behaviour except for the end-member compounds. The complex magnetic features appear to originate from composition inhomogeneity, local magnetic order in the chains of octahedra being dependent on small clusters of the same transition metal ion and the delicate energy balance that clearly exists between the two ordered configurations in the mid-composition region where $x$ is near to 0.5 .
\end{abstract}

\section{Introduction}

The mineral schafarzikite, $\mathrm{FeSb}_{2} \mathrm{O}_{4}$, has the low-dimensional structure shown in Fig. 1 (tetragonal, $P 4_{2} / m b c, a=8.62 \AA$ and $c=5.91 \AA)^{1}$ in which chains of edge-linked $\mathrm{FeO}_{6}$ octahedra along [001] enclose channels which are parallel to the chains and have a diameter of approximately $4 \AA$. The chains of octahedra are connected by $\mathrm{SbO}_{3}$ trigonal pyramids. $\mathrm{The}^{3 b^{3+}}$ lone pairs (e) are directed into the channels and provide pseudotetrahedral $\mathrm{SbO}_{3} \mathrm{e}$ coordination. Strong intrachain magnetic exchange (primarily direct orbital overlap between adjacent $\mathrm{Fe}^{2+}$ ions) results in A-type magnetic order (Fig. 2a) below the Néel temperature, $T_{\mathrm{N}}=46 \mathrm{~K}^{2,3}$

Related $\mathrm{MSb}_{2} \mathrm{O}_{4}$ materials ( $\mathrm{M}=$ magnetic transition metal) are known for $\mathrm{M}=\mathrm{Mn}, \mathrm{Co}, \mathrm{Ni}, \mathrm{Cu}$ and $\mathrm{Zn}^{4}{ }^{4-9}$ All order magnetically at low temperatures except for $\mathrm{CuSb}_{2} \mathrm{O}_{4}$, which shows no long range order above $2 \mathrm{~K}^{9}$ and the diamagnetic $\mathrm{ZnSb}_{2} \mathrm{O}_{4}$. Whereas the phases with $\mathrm{M}=\mathrm{Mn}$, Fe display predominantly A-type magnetic order (Fig. 2a), the $\mathrm{M}=\mathrm{Co}, \mathrm{Ni}$ phases are C-type antiferromagnets (Fig. 2b). ${ }^{1,10,11}$ In fact, the

School of Chemistry, University of Birmingham, Birmingham B15 2TT, UK.

E-mail: c.greaves@bham.ac.uk

$\dagger$ Electronic supplementary information (ESI) available. See DOI: 10.1039/ c5tc03333k

\# Current address: CSEC and School of Chemistry, University of Edinburgh, Edinburgh EH9 3FD, UK.

$\S$ Authors have made equal contributions to the paper.
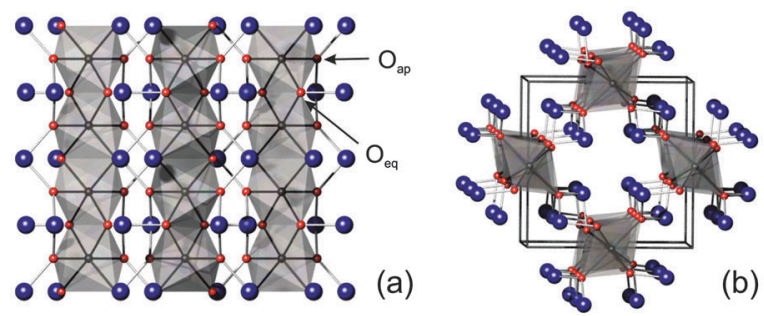

Fig. $1 \mathrm{MSb}_{2} \mathrm{O}_{4}$ structure viewed (a) along [100] and (b) approximately along [001]. M - grey octahedra, $\mathrm{Sb}$ - large blue spheres, $\mathrm{O}$ - red spheres.

magnetic order is quite complex and $\mathrm{FeSb}_{2} \mathrm{O}_{4}$, for example, may show a small rotation of the magnetic moment vectors to introduce some G-type character. ${ }^{1,12}$ It has been suggested that the nature of the direct exchange within the chains - size of cation, M-M separation distance and occupancy of the $t_{2 g}$ orbitals - is responsible for the change in magnetic order. ${ }^{11}$

Recently, attempts to functionalise some materials by creating mixed $\mathrm{M}^{2+} / \mathrm{M}^{3+}$ oxidation states have been reported via substitution of $\mathrm{Pb}^{2+}$ for $\mathrm{Sb}^{3+}$ for $\mathrm{M}=\mathrm{Mn}$, Fe and $\mathrm{Co}^{11-13}$ Although $\mathrm{Sb}^{3+}$ was found to be preferentially oxidised to $\mathrm{Sb}^{5+}$ for $\mathrm{M}=\mathrm{Mn}^{13}$ and $\mathrm{Co},{ }^{11}$ Whitaker et al. ${ }^{12}$ showed that mixed $\mathrm{Fe}^{2+} / \mathrm{Fe}^{3+}$ states exist in $\mathrm{FeSb}_{2-x} \mathrm{~Pb}_{x} \mathrm{O}_{4}$.

Little attention has been given to phases containing a mixture of transition metal ions, although a magnetic study of $\mathrm{Mn}_{1-x} \mathrm{~V}_{x} \mathrm{Sb}_{2} \mathrm{O}_{4}$ revealed weak ferromagnetism, ${ }^{14}$ which is 
(a)

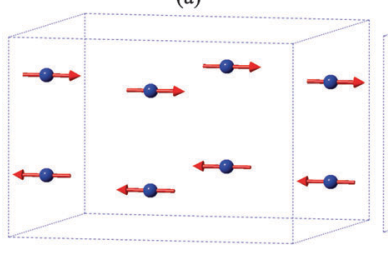

(c) (b)

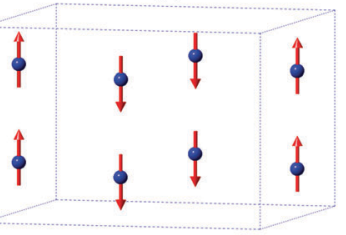

(d)

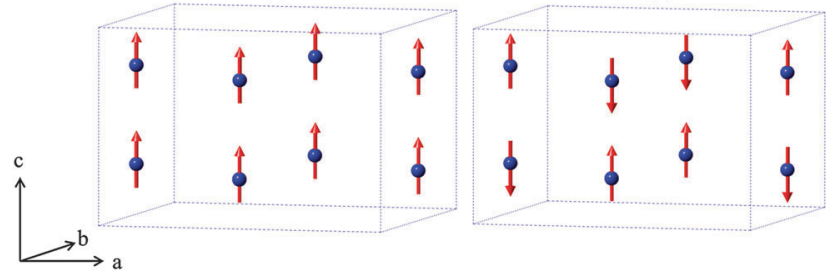

Fig. 2 The four possible collinear spin alignments generating magnetic structures: (a) A-type, (b) C-type, (c) F-type and (d) G-type.

likely to result from a canted antiferromagnetic ground state. The change in magnetic order from A-type $(\mathrm{M}=\mathrm{Mn}, \mathrm{Fe})$ to C-type ( $\mathrm{M}=\mathrm{Co}$, Ni) suggests that the size of $\mathrm{M}^{2+}$ ions - and/or their electron density - is important in determining the magnitude of magnetic exchange interactions. We have explored in more detail the nature of this transition between A-type and C-type by studying the structure and magnetic properties of two series of compounds containing mixed $\mathrm{M}^{2+}$ cations: $\mathrm{Fe}_{x} \mathrm{Co}_{1-x} \mathrm{Sb}_{2} \mathrm{O}_{4}$ $(x=0.0,0.25,0.50,0.75,1.0)$ and $\mathrm{Mn}_{x} \mathrm{Co}_{1-x} \mathrm{Sb}_{2} \mathrm{O}_{4}(x=0.0,0.2$, $0.40 .5,0.6,0.8,1.0)$; we report here the complex nature of an interesting, continuous magnetic transition that occurs between A-type and C-type order in both series.

\section{Experimental}

Polycrystalline samples of $\mathrm{M}_{x}^{\prime} \mathrm{Co}_{1-x} \mathrm{Sb}_{2} \mathrm{O}_{4}\left(\mathrm{M}^{\prime}=\mathrm{Mn}, \mathrm{Fe}\right)$ were synthesised by heating homogenous mixtures of $\mathrm{MnO}(99 \%$, Aldrich), $\mathrm{CoO}$ ( $>99 \%$, Aldrich), $\mathrm{Sb}_{2} \mathrm{O}_{3}$ (99\% Reagent Plus, Aldrich), $\mathrm{Fe}_{2} \mathrm{O}_{3}$ ( $\geq 99 \%$, Sigma-Aldrich) and $\mathrm{Sb}$ (100 mesh, $99.5 \%$, Sigma-Aldrich) in the appropriate stoichiometric amounts; reagents were all dried prior to use. Reaction mixtures were heated in evacuated sealed silica tubes containing alumina inserts to prevent reaction with the silica. The mixtures were heated for periods which varied from 6 hours to 36 hours at $700{ }^{\circ} \mathrm{C}$ with intermittent grinding.

X-Ray powder diffraction (XRPD) data were collected on a Bruker D8 diffractometer (PSD: Lynxeye, $\mathrm{Cu}-\mathrm{K}_{\alpha 1}$, Ge monochromator) in planar transmission mode; absorption corrections were applied where structure refinements were conducted. Neutron powder diffraction (NPD) data were obtained from ILL, Grenoble (D2B, $\lambda=1.59432 \AA$, ambient and $4 \mathrm{~K}$ for $\mathrm{M}^{\prime}=\mathrm{Mn}[x \leq 0.8]$ and $\mathrm{M}^{\prime}=\mathrm{Fe}[x=0.5]$ ), PSI Zurich (SINQ, $\lambda=1.88518 \AA, \mathrm{M}^{\prime}=\mathrm{Fe}$, $x=0.25$ and 0.75), and ISIS, RAL, UK (GEM for $\mathrm{MnSb}_{2} \mathrm{O}_{4}$ ). The wavelengths were calibrated based on XRPD refinements on the materials under investigation. The ILL data were deconvoluted into a high intensity, full detector (HI) and lower intensity, greater peak resolution (HR) data sets to reduce the low angle peak asymmetry, which was significant for some low angle magnetic reflections. The use of several NPD diffractometers resulted in low temperature data being collected at $2 \mathrm{~K}, 4 \mathrm{~K}$, and $5 \mathrm{~K}$. In this paper, these data will be referred to as low temperature (LT) datasets.

The Rietveld method ${ }^{15}$ was used to derive the nuclear and magnetic structures of each compound with the aid of the general structures analysis system (GSAS) ${ }^{16}$ and EXPGUI interface. ${ }^{17}$ Background intensity was modelled using a shifted Chebyschev polynomial with between 15 and 25 terms, while peak shapes were modelled using a pseudo-Voigt function. It was necessary to include preferred orientation for both XRPD and NPD data using the March-Dollase formulation incorporated within GSAS, constrained to be equal for both magnetic and nuclear phases. Due to the low total scattering from the $\mathrm{Mn} / \mathrm{Co}$ site for $x=0.4(b=0.004 \mathrm{fm})$ it was necessary to fix the $\mathrm{M}$ site thermal displacement parameter to a value consistent with other $\mathrm{Mn}$ : Co ratios. The magnetic structure was modelled using a second unit cell (P1) containing only magnetic cations, with appropriate constraints between magnetic moments. This phase was constrained to comply with the nuclear unit cell dimensions.

Magnetic susceptibility data were acquired using a materials properties measurement system (MPMS, Quantum Design XL) under field cooled (FC) and zero field cooled (ZFC) conditions with applied fields of 100 Oe or 500 Oe. No corrections for diamagnetism were applied since they are too small to provide a significant effect. A cooling and heating rate of $10 \mathrm{~K} \mathrm{~min}^{-1}$ was used, with measurements taken in 'Sweep' mode. The polycrystalline sample $(\sim 50 \mathrm{mg})$ was contained in a gelatin capsule, while sample movement was suppressed using PTFE tape.

\section{Results and discussion}

\subsection{Crystallographic and magnetic structures}

All XRPD patterns indicated single phase products consistent with $\mathrm{P4}_{2} / \mathrm{mbc}$ symmetry. NPD structural refinements were based on the structure of $\operatorname{CoSb}_{2} \mathrm{O}_{4}{ }^{11}$ as a starting model, with the $\mathrm{Mn}: \mathrm{Co}$ and Fe:Co site occupancies constrained to the stoichiometry of the starting reagents weighed out. As expected, no evidence for cation order within the chains of $\mathrm{MO}_{6}$ octahedra was apparent. A small $\mathrm{Fe}_{3} \mathrm{O}_{4}$ impurity $(\sim 1 \mathrm{wt} \%)$ was present in $\mathrm{Fe}_{0.75} \mathrm{Co}_{0.25} \mathrm{Sb}_{2} \mathrm{O}_{4}$ and nuclear and magnetic contributions for magnetite were therefore included in the refinements. This contamination is commonly observed for iron rich variants. ${ }^{1,12}$ In the refinement data below, $\mathrm{O} 1$ and $\mathrm{O} 2$ correspond to equatorial and apical oxygen ions, respectively, as shown in Fig. 1. All atoms were modelled using isotropic displacement parameters (IDPs) except for $\mathrm{O} 2$ in $\mathrm{Fe}_{x} \mathrm{Co}_{1-x} \mathrm{Sb}_{2} \mathrm{O}_{4}$, where significant anisotropy was indicated for $x=0.25$ and $x=0.50$ and was therefore allowed in these refinements. In the case of $x=0.75$ there was no significant difference to the anisotropic displacement parameters for $\mathrm{O} 2$ at $2 \mathrm{~K}$, hence isotropic displacement parameters were reinstated. The anisotropic displacement parameters for $\mathrm{O} 2$ represent enhanced displacements in the $a b$ plane as shown in Fig. $\mathrm{S} 1$ (ESI $\dagger$ ). For $\mathrm{Mn}_{0.8} \mathrm{Co}_{0.2} \mathrm{Sb}_{2} \mathrm{O}_{4}$, 
NPD data showed additional weak peaks, corresponding to a very small (0.01 wt\%) MnO impurity; this was included as a cubic $F m \overline{3} m$ phase at $300 \mathrm{~K}$ (above the Néel temperature, $120 \mathrm{~K}$ ), and as a single (nuclear and magnetic) monoclinic $(C 2 / c)$ phase for the low temperature dataset.

The refined structural parameters at $300 \mathrm{~K}$ are given in Tables 1 and 2 for $\mathbf{M}^{\prime}=\mathrm{Fe}$ and $\mathrm{Mn}$, respectively. Typical diffraction profiles at $300 \mathrm{~K}$ (for the $x=0.50$ member of both series) are shown in Fig. 3. The variation in the unit cell parameters with composition, determined from the $300 \mathrm{~K}$ and LT data, are shown in Fig. 4 and Fig. S2 (ESI $\dagger$ ), respectively. For the Mn series, the unit cell size increases regularly with Mn content, in accordance with ionic radii considerations: $0.745 \AA$ and $0.830 \AA$ for high spin, 6-coordinate $\mathrm{Co}^{2+}$ and $\mathrm{Mn}^{2+}$, respectively. ${ }^{18}$ The $a$ parameter for $\mathrm{Fe}_{x} \mathrm{Co}_{1-x} \mathrm{Sb}_{2} \mathrm{O}_{4}$ increases less rapidly than the $\mathrm{Mn}$ series, which again reflects the smaller radius for $\mathrm{Fe}^{2+}, 0.780 \AA{ }^{18}$ compared with that for $\mathrm{Mn}^{2+}$. However, the $c$ parameter for $\mathrm{Fe}_{x} \mathrm{Co}_{1-x} \mathrm{Sb}_{2} \mathrm{O}_{4}$ surprisingly decreases slightly as $x$ increases; this will be discussed later with respect to the magnetic properties.

The structural and magnetic parameters determined from low temperature refinements are collected in Tables 3 and 4 . Diffraction profiles for the $x=0.50$ member of both series are shown in Fig. 5. The small, broad peaks observed in Fig. 5(b) (at $2 \theta \sim 40^{\circ}$ and $47^{\circ}$ ) are from the cryostat used. For $\mathrm{Mn}_{x} \mathrm{Co}_{1-x} \mathrm{Sb}_{2} \mathrm{O}_{4}$, the IDPs for $\mathrm{Sb}$ and the $\mathrm{Mn} / \mathrm{Co}$ site were

Table 1 Refined parameters from NPD refinement for $\mathrm{Fe}_{x} \mathrm{CO}_{1-x} \mathrm{Sb}_{2} \mathrm{O}_{4}$ in $P 4_{2} / m b c$ at $300 \mathrm{~K}$

\begin{tabular}{lllll}
\hline$x$ & & 0.25 & 0.50 & 0.75 \\
\hline$a / \AA$ & & $8.5265(1)$ & $8.5457(1)$ & $8.5728(2)$ \\
$c / \AA$ & & $5.92675(9)$ & $5.91843(9)$ & $5.9170(1)$ \\
$\mathrm{Fe} / \mathrm{Co}(4 \mathrm{~d})$ & $U_{\text {iso }} \times 100 / \AA^{2}$ & $1.08(5)$ & $1.24(4)$ & $1.19(3)$ \\
$\mathrm{Sb}(8 \mathrm{~h})$ & $x$ & $0.1757(1)$ & $0.1748(2)$ & $0.1761(2)$ \\
& $y$ & $0.1650(1)$ & $0.1647(2)$ & $0.1651(2)$ \\
& $U_{\text {iso }} \times 100 / \AA^{2}$ & $1.37(3)$ & $1.38(3)$ & $1.38(3)$ \\
$\mathrm{O} 1_{\text {eq }}(8 \mathrm{~h})$ & $x$ & $0.0995(1)$ & $0.0987(1)$ & $0.0996(1)$ \\
& $y$ & $0.6398(1)$ & $0.6399(1)$ & $0.6410(1)$ \\
$\mathrm{O} 2_{\text {ap }}(8 \mathrm{~g})$ & $U_{\text {iso }} \times 100 / \AA^{2}$ & $1.48(3)$ & $1.50(3)$ & $1.63(3)$ \\
& $U_{11} / U_{22} \times 100 / \AA^{2}$ & $0.67889(8)$ & $0.6792(1)$ & $0.67896(9)$ \\
$\chi^{2}, R_{\text {wp }}$ & $U_{33} \times 100 / \AA^{2}$ & $1.59(9)$ & $2.57(5)$ & $2.53(5)$ \\
& & $1.92,0.040$ & $5.05(7)$ & $1.42(8)$ \\
& & & & $3.77,0.041$
\end{tabular}

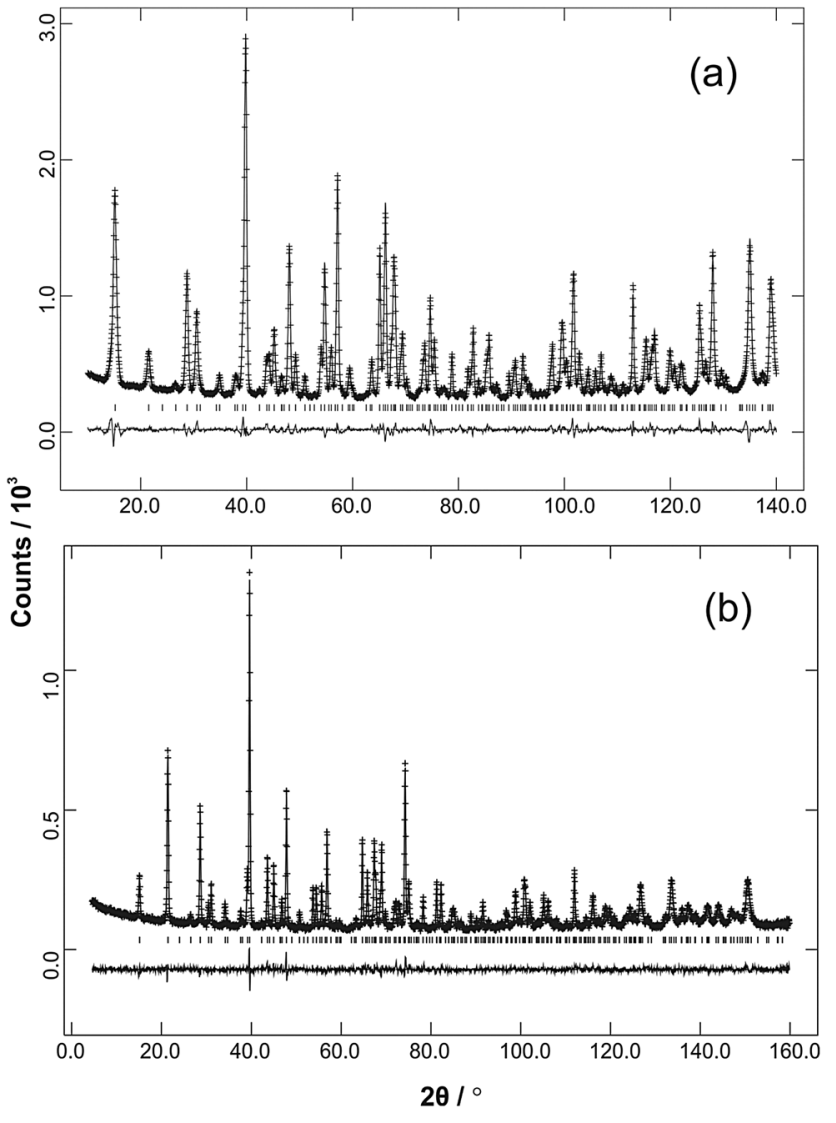

Fig. 3 Ambient temperature NPD data (observed, calculated and difference profiles) from (a) $\mathrm{Fe}_{0.50} \mathrm{Co}_{0.50} \mathrm{Sb}_{2} \mathrm{O}_{4}(\lambda=1.594 \AA)$ and (b) $\mathrm{Mn}_{0.5} \mathrm{Co}_{0.5} \mathrm{Sb}_{2} \mathrm{O}_{4}(\lambda=1.593 \AA)$.

typically small and sometimes slightly negative. At low temperatures, IDPs are inherently small and the low scattering from $\mathrm{Co} / \mathrm{Mn}$ could explain this problem for the transition metal site. However, the IDP values for all ions in the $\mathbf{M}^{\prime}=\mathbf{M n}$ series are smaller than equivalent values for $\mathbf{M}^{\prime}=\mathrm{Fe}$ and this may reflect neutron absorption effects. Where IDP values were negative, they were constrained to zero, the lowest physically allowed value. It is seen that for both series, the magnetic structure changes from C-type to A-type as $x$ increases. The change is not sudden, and an intermediate region can be

Table 2 Refined parameters from NPD refinement for $\mathrm{Mn}_{x} \mathrm{Co}_{1-x} \mathrm{Sb}_{2} \mathrm{O}_{4}$ in $P 4_{2} / m b c$ at $300 \mathrm{~K}$

\begin{tabular}{|c|c|c|c|c|c|c|c|}
\hline$x$ & & 0.2 & 0.4 & 0.5 & 0.6 & 0.8 & 1.0 \\
\hline$a / \AA$ & & $8.5348(1)$ & $8.5775(2)$ & $8.5976(2)$ & $8.6187(1)$ & $8.6585(2)$ & $8.7107(2)$ \\
\hline$c / \AA$ & & $5.93956(9)$ & $5.9534(1)$ & $5.9603(1)$ & $5.96720(8)$ & $5.9788(1)$ & $5.9967(2)$ \\
\hline $\mathrm{Mn} / \mathrm{Co}(4 \mathrm{~d})$ & $U_{\text {iso }} \times 100 / \AA^{2}$ & $1.3(2)$ & $0.81^{a}$ & $0.81^{a}$ & $0.57(1)$ & $0.70(8)$ & $0.72(4)$ \\
\hline \multirow[t]{3}{*}{$\mathrm{Sb}(8 \mathrm{~h})$} & $x$ & $0.1758(2)$ & $0.1773(2)$ & $0.1779(2)$ & $0.1782(2)$ & $0.1790(2)$ & $0.1795(1)$ \\
\hline & $y$ & $0.1649(2)$ & $0.1651(2)$ & $0.1656(2)$ & $0.1664(2)$ & $0.1664(2)$ & $0.1674(1)$ \\
\hline & $U_{\text {iso }} \times 100 / \AA^{2}$ & $0.79(3)$ & $0.93(4)$ & $1.06(3)$ & $1.01(3)$ & $0.84(4)$ & $1.03(2)$ \\
\hline \multirow[t]{3}{*}{$\mathrm{O} 1_{\mathrm{eq}}(8 \mathrm{~h})$} & $x$ & $0.0988(2)$ & $0.0984(2)$ & $0.0990(2)$ & $0.0995(2)$ & $0.0994(2)$ & $0.0997(1)$ \\
\hline & $y$ & $0.6407(2)$ & $0.6425(2)$ & $0.6427(2)$ & $0.6430(2)$ & $0.6442(2)$ & $0.6448(1)$ \\
\hline & $U_{\text {iso }} \times 100 / \AA^{2}$ & $0.93(3)$ & $1.04(4)$ & $1.18(3)$ & $1.11(3)$ & $1.03(4)$ & $1.16(3)$ \\
\hline \multirow[t]{2}{*}{$\mathrm{O} 2_{\text {ap }}(8 \mathrm{~g})$} & $x$ & $0.6794(1)$ & $0.6798(1)$ & $0.6796(1)$ & $0.6799(1)$ & $0.6800(1)$ & $0.68044(7)$ \\
\hline & $U_{\text {iso }} \times 100 / \AA^{2}$ & $1.34(3)$ & $1.36(3)$ & $1.52(3)$ & $1.49(3)$ & $1.38(3)$ & $1.41(3)$ \\
\hline$\chi^{2}, R_{\mathrm{wp}}$ & & $1.98,0.047$ & $2.20,0.042$ & $4.17,0.045$ & $2.24,0.049$ & $1.71,0.043$ & $1.88,0.025$ \\
\hline
\end{tabular}

${ }^{a}$ Constrained equal to the average of other samples in the series. 


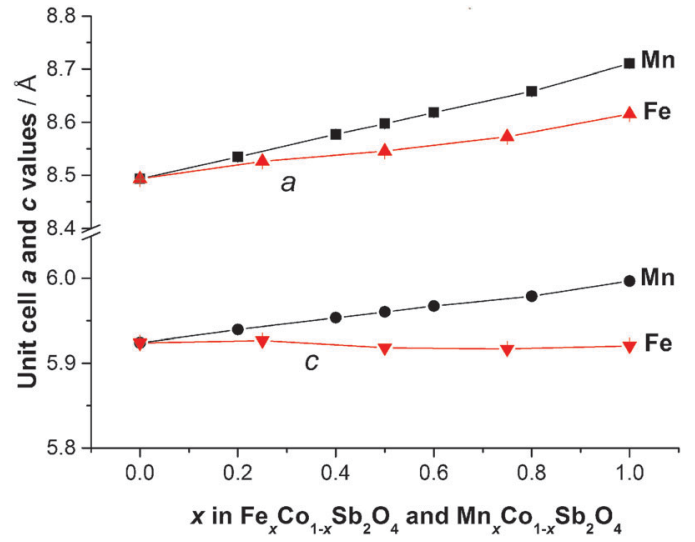

Fig. 4 Variation of unit cell edge lengths for $\mathrm{Mn}_{x} \mathrm{Co}_{1-x} \mathrm{Sb}_{2} \mathrm{O}_{4}$ and $\mathrm{Fe}_{x} \mathrm{CO}_{1-x} \mathrm{Sb}_{2} \mathrm{O}_{4}$ at $300 \mathrm{~K}$. Errors are hidden by the symbols.

Table 3 Refined parameters from NPD refinement for $\mathrm{Fe}_{x} \mathrm{CO}_{1-x} \mathrm{Sb}_{2} \mathrm{O}_{4}$ at low temperature $(2 \mathrm{~K}$ for $x=0.25,0.75 ; 4 \mathrm{~K}$ for $x=0.5$ )

\begin{tabular}{lllll}
\hline$x$ & & 0.25 & 0.50 & 0.75 \\
\hline$a / \AA$ & & $8.5172(1)$ & $8.5382(1)$ & $8.5677(1)$ \\
$c / \AA$ & & $5.92236(8)$ & $5.90999(9)$ & $5.90455(9)$ \\
$\mathrm{Fe} / \mathrm{Co}(4 \mathrm{~d})$ & $U_{\text {iso }} \times 100 / \AA^{2}$ & $0.53(4)$ & $0.30(5)$ & $0.58(3)$ \\
$\mathrm{Sb}(8 \mathrm{~h})$ & $x$ & $0.1753(1)$ & $0.1753(2)$ & $0.1753(2)$ \\
& $y$ & $0.1647(1)$ & $0.1649(2)$ & $0.1647(2)$ \\
& $U_{\text {iso }} \times 100 / \AA^{2}$ & $0.57(3)$ & $0.19(4)$ & $0.52(3)$ \\
$\mathrm{O} 1_{\text {eq }}(8 \mathrm{~h})$ & $x$ & $0.0995(1)$ & $0.0990(2)$ & $0.0995(1)$ \\
& $y$ & $0.6404(1)$ & $0.6406(2)$ & $0.6416(1)$ \\
& $U_{\text {iso }} \times 100 / \AA^{2}$ & $0.82(3)$ & $0.39(4)$ & $0.81(3)$ \\
$\mathrm{O} 2_{\text {ap }}(8 \mathrm{~g})$ & $x$ & $0.67834(7)$ & $0.6788(1)$ & $0.67837(9)$ \\
& $U_{11} / U_{22} \times 100 / \AA^{2}$ & $0.96(3)^{a}$ & $0.77(6)$ & $1.20(5)$ \\
& $U_{33} \times 100 / \AA^{2}$ & - & $0.23(8)$ & $0.68(8)$ \\
$\mathrm{Moment}\left(\mu_{\mathrm{B}}\right)$ & $\mathrm{C}_{z}$ & $3.03(1)$ & $1.86(2)$ & $1.27(1)$ \\
& $\mathrm{A}_{x}$ & 0 & $1.02(5)$ & $2.51(2)$ \\
& Total & $3.03(1)$ & $2.12(4)$ & $2.81(3)$ \\
$\chi^{2}, R_{\mathrm{wp}}$ & & $4.24,0.043$ & $2.76,0.055$ & $4.44,0.046$ \\
${ }^{a} U_{\text {iso. }}$ & & & & \\
& & & &
\end{tabular}

identified in which the magnetic structure can be represented as a mixture of both types: C-type with the moment along $z$ (and $-z$ ), and A-type with moments along $x$ (and $-x$ ) as seen in

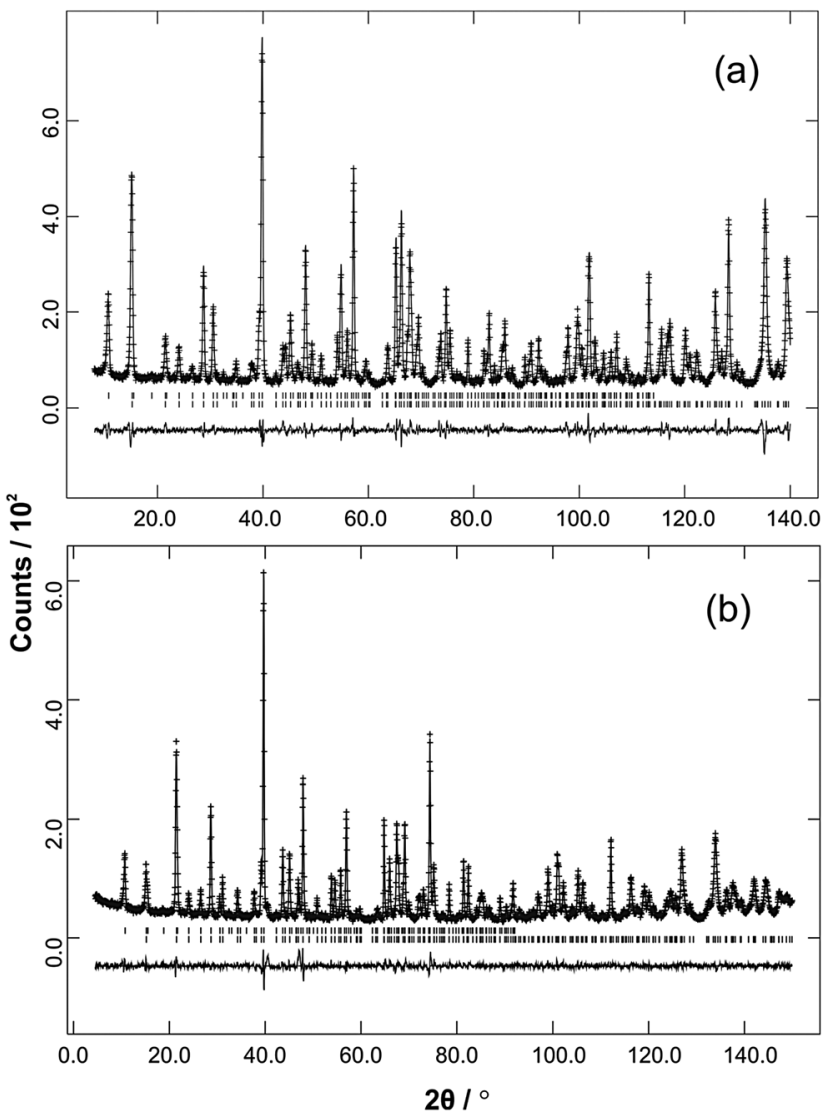

Fig. 5 Low temperature NPD data (observed, calculated and difference profiles) from (a) $\mathrm{Fe}_{0.5} \mathrm{Co}_{0.5} \mathrm{Sb}_{2} \mathrm{O}_{4}(\lambda=1.594 \AA)$ and (b) $\mathrm{Mn}_{0.5} \mathrm{Co}_{0.5} \mathrm{Sb}_{2} \mathrm{O}_{4}(\lambda=$ $1.593 \AA$ ). Reflection positions for the magnetic phase are above the nuclear reflections. These relate to the $P 1$ magnetic unit cell used to allow simultaneous refinement of $\mathrm{A}$ - and $\mathrm{C}$-type magnetic contributions. The positions therefore correspond to the crystallographic cell but with no absences.

Tables 3 and 4. Summing the moment vectors provides an alternative description in which the moments rotate from the $z$-axis to the $x$-axis. Fig. 6 shows the rotations in adjacent chains of octahedra that convert C- to A-type order; Fig. 7 shows the change in orientation (rotation angle) as a function

Table 4 Refined parameters from NPD refinement for $\mathrm{Mn}_{x} \mathrm{Co}_{1-x} \mathrm{Sb}_{2} \mathrm{O}_{4}$ at $5 \mathrm{~K}$

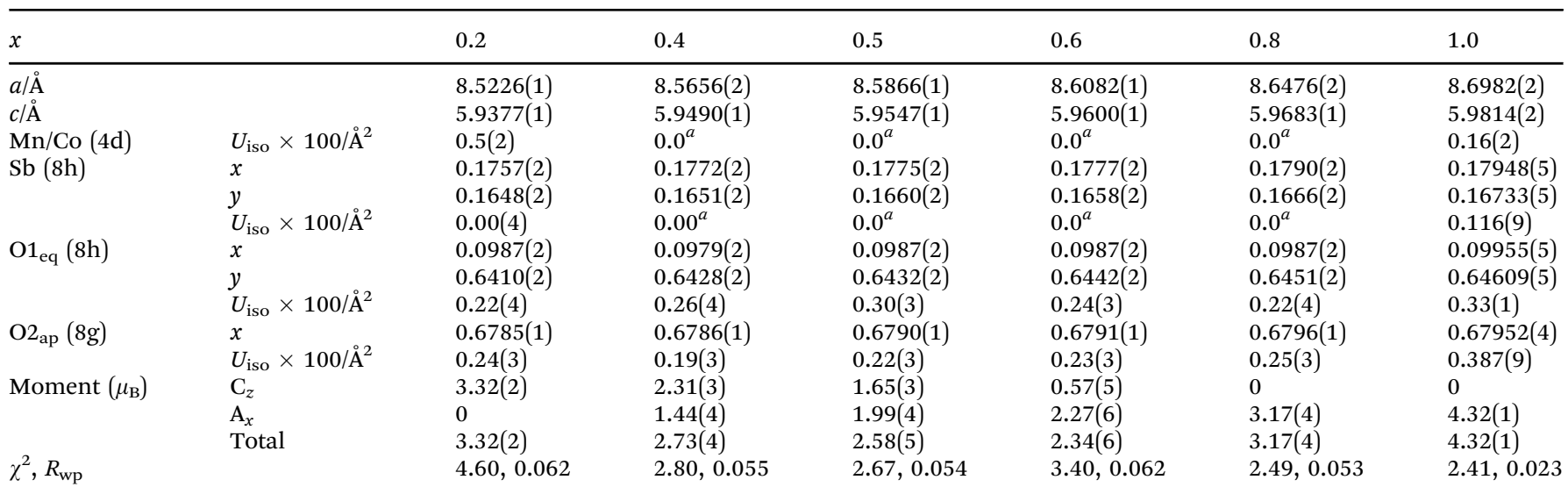

${ }^{a}$ Constrained to 0.0 because of slightly negative refined value. 


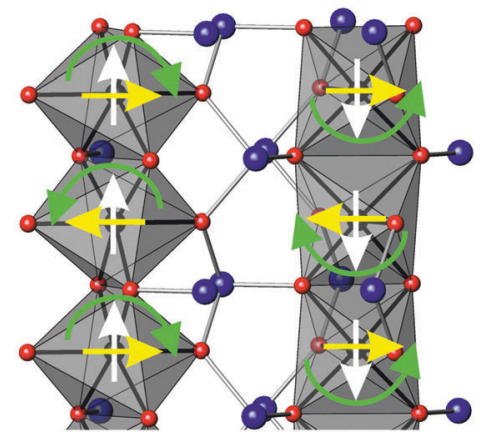

Fig. 6 Rotation of magnetic moments (green arrows) in two adjacent chains of octahedra that convert C-type order (white arrows) to A-type (yellow arrows).

of composition for both series. The overall moment for all samples is plotted in Fig. 8 and includes data for $\mathrm{CoSb}_{2} \mathrm{O}_{4}{ }^{11}$ and $\mathrm{FeSb}_{2} \mathrm{O}_{4}{ }^{12}$ Given the change from A-type order to C-type as we cross the transition series from $\mathrm{Mn}^{2+}$ to $\mathrm{Ni}^{2+}$, we might expect that the

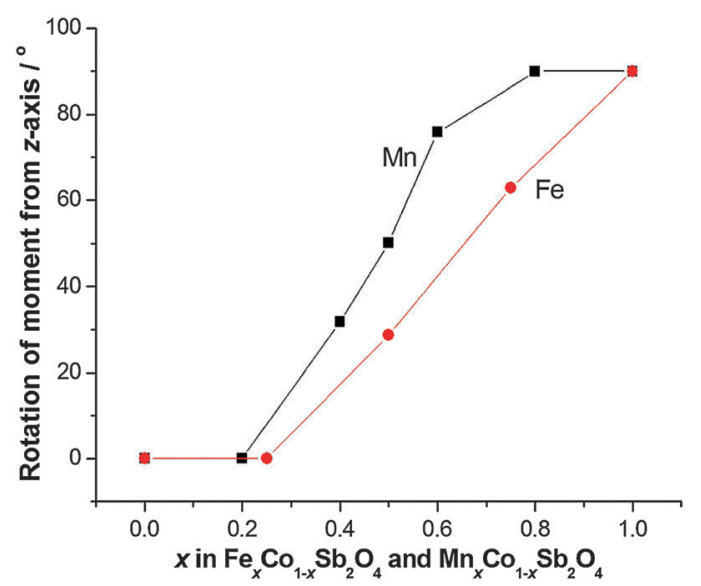

Fig. 7 Angle between magnetic moments and the $z$-axis as a function of $x$ for $\mathrm{Mn}_{x} \mathrm{Co}_{1-x} \mathrm{Sb}_{2} \mathrm{O}_{4}$ and $\mathrm{Fe}_{x} \mathrm{Co}_{1-x} \mathrm{Sb}_{2} \mathrm{O}_{4}$.

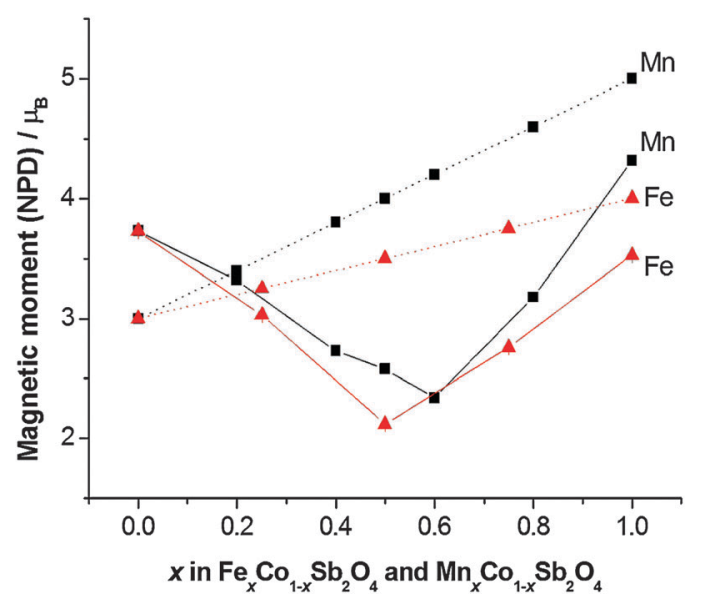

Fig. 8 Comparison of experimental magnetic moments from NPD data (solid lines) and $2 \mathrm{~S}$ (dotted lines) for $\mathrm{Mn}_{x} \mathrm{Co}_{1-x} \mathrm{Sb}_{2} \mathrm{O}_{4}$ and $\mathrm{Fe}_{x} \mathrm{CO}_{1-x} \mathrm{Sb}_{2} \mathrm{O}_{4}$. Errors are hidden by the symbols. substitution of $\mathrm{Mn}^{2+}$ for $\mathrm{Co}^{2+}$ in $\mathrm{CoSb}_{2} \mathrm{O}_{4}$ would stabilise the A-type order more than the corresponding substitution of $\mathrm{Fe}^{2+}$. Indeed, this is supported by Fig. 7, since the transition from A- to C-type order occurs at a lower substitution level for $\mathrm{Mn}^{2+}$. However, the difference is not large, and smaller than we would expect.

It is useful to consider the magnetic exchange interactions in order to discuss the change from $\mathrm{C}$ - to A-type behaviour as $x$ increases for both series, Fig. 7. Direct exchange is important and relates to direct overlap of $t_{2 g}$ orbitals of the transition metal ions within the edge-linked octahedra. This will decrease in the order $\mathrm{Mn}^{2+}>\mathrm{Fe}^{2+}>\mathrm{Co}^{2+}$ based solely on the number of unpaired $t_{2 g}$ electrons, but will also depend on the extent of orbital overlap. The $\mathbf{M}-\mathbf{M}$ distance within the chains is equal to $c / 2$, and Fig. 4 and Fig. S2 (ESI $\dagger$ ) show that despite the fact that $\mathrm{Fe}^{2+}$ is larger than $\mathrm{Co}^{2+}, c$ decreases slightly as $\mathrm{Co}^{2+}$ is replaced by $\mathrm{Fe}^{2+}$. This would be expected to increase the antiferromagnetic intrachain interactions for $\mathrm{Fe}_{x} \mathrm{Co}_{1-x} \mathrm{Sb}_{2} \mathrm{O}_{4}$ and oppose the effect of the decrease in number of $\mathrm{t}_{2 \mathrm{~g}}$ electrons on $\mathrm{Fe}^{2+}$ relative to $\mathrm{Mn}^{2+}$; it rationalises the similar compositions ( $x$ values) for the change in magnetic order in the two series. The elongated octahedral coordination for the transition metal ions is a consequence of the structure, and the reason for the decrease in $c$ is unclear. It may, however, reflect an enhanced distortion that results from the small Jahn-Teller effect that can occur for high spin $\mathrm{Fe}^{2+}$ ions. The $\mathrm{M}-\mathrm{O}-\mathrm{M}(\mathrm{M}=\mathrm{Co}$, $\mathrm{Mn}, \mathrm{Fe}$ ) superexchange (SE) interactions within the chains will favour ferromagnetic intrachain order (C-type order) but will be weaker than the direct exchange for $\mathrm{Mn}^{2+}$ and $\mathrm{Fe}^{2+}$ ions. For all compositions, the $\mathrm{M}-\mathrm{O}-\mathrm{M}$ angle is close to $90^{\circ}$, and the $\mathrm{M}-\mathrm{O}_{\text {eq }}$ bond lengths show no behaviour in either series (Fig. 9) to suggest a large change to the strength of this exchange mechanism. Since the $\mathrm{M}-\mathrm{O}_{\mathrm{eq}}$ distance depends on both $a$ and $c$ parameters, it is seen that the unusual decrease in $c$, caused by the substitution of $\mathrm{Fe}^{2+}$ ions, is not reflected in the $\mathrm{M}-\mathrm{O}_{\mathrm{eq}}$ distances. The M-O-Sb-O-M super-superexchange (SSE) interaction will favour an anti-parallel alignment of spins in nearestneighbour octahedral chains, acting within both [110] and [111] directions; this is the origin of A- and C-type ground states, as

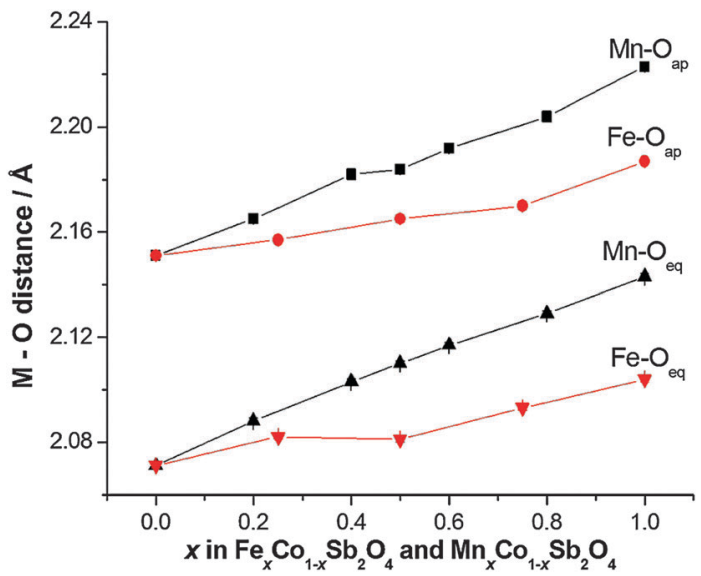

Fig. 9 Equatorial and apical $\mathrm{M}-\mathrm{O}$ distances for $\mathrm{Mn}_{x} \mathrm{CO}_{1-x} \mathrm{Sb}_{2} \mathrm{O}_{4}$ and $\mathrm{Fe}_{x} \mathrm{CO}_{1-x} \mathrm{Sb}_{2} \mathrm{O}_{4}$. Errors are hidden by the symbols. 
opposed to G- or F-type (Fig. 2). To a first approximation this interaction will depend on the lattice $a$-parameter, with a small contribution from $c$.

The overall magnetic structure is a competition between these three magnetic interactions, dependent on both electronic $t_{2 g}$ configuration, and lattice parameters. For $\mathrm{CoSb}_{2} \mathrm{O}_{4}$, the $a / c$ ratio (1.432) is lower than for $\mathrm{MnSb}_{2} \mathrm{O}_{4}$ (1.453) or $\mathrm{FeSb}_{2} \mathrm{O}_{4}$ (1.455), therefore the inter-chain SSE and $90^{\circ} \mathrm{SE}$ interactions promote C-type order. For $\mathrm{M}=\mathrm{Mn}$ and $\mathrm{Fe}$, the direct exchange interaction is most significant, promoting an A-type ground state.

A remarkable feature of Fig. 8 is that the moment derived from NPD data (corresponding ideally to $2 S$ for complete quenching of any orbital component) varies with $x$ such that it passes through a minimum near the mid-point, $x \sim 0.5$ for both series. The end member moments are as expected: the moment for $\mathrm{Co}^{2+}$ in $\mathrm{CoSb}_{2} \mathrm{O}_{4}$ is higher than $2 S$ because of the high orbital contribution that exists for the ${ }^{4} \mathrm{~T}_{1 \mathrm{~g}}$ ground state; the moments of $\mathrm{MnSb}_{2} \mathrm{O}_{4}$ and $\mathrm{FeSb}_{2} \mathrm{O}_{4}$ are both reduced below $2 S$ because of covalence and low temperature quantum effects. At the minima in the moments, the values are approximately $1.5 \mu_{\mathrm{B}}$ lower than the respective values of $2 S$, which is highly significant given the high values for $\mathrm{Co}^{2+}$ ions. We attribute these moments to incomplete magnetic order within these materials. These minima correspond to an $a / c$ ratio of 1.444 in both materials, suggesting that at this ratio the competition between inter- and intra-chain ordering compensate each other. Given the small energy difference between A- and C-type order at these compositions, it is plausible that composition inhomogeneity may result in regions of disorder or short-range order. In addition, the natural statistical occurrence of sequences such as -Co-Co-Co- within the chains may also result in short-range order that is inconsistent with the overall long-range magnetic order. The observed magnetic model corresponds to a combination of $\Gamma_{5}$ and $\Gamma_{10}$ irreducible representations, indicating the presence of more than one second-order phase transition from Landau theory. Some supporting evidence for complex magnetic behaviour is found in magnetic susceptibility data (vide infra).

\subsection{Magnetic susceptibility}

Magnetic susceptibility data for samples $\mathrm{Fe}_{x} \mathrm{Co}_{1-x} \mathrm{Sb}_{2} \mathrm{O}_{4}$ and $\mathrm{Mn}_{x} \mathrm{Co}_{1-x} \mathrm{Sb}_{2} \mathrm{O}_{4}$ are shown in Fig. 10 and 11, respectively. Susceptibility data for the end members $(\mathrm{M}=\mathrm{Co}, \mathrm{Fe}, \mathrm{Mn})$ have previously been reported, ref. 11, 19 and 20, respectively. The $\mathrm{Fe}_{x} \mathrm{Co}_{1-x} \mathrm{Sb}_{2} \mathrm{O}_{4}$ samples show a transition to a canted antiferromagnetic ground state with a Néel temperature $\left(T_{\mathrm{N}}\right)$ of approximately $55 \mathrm{~K}$. The magnitude of the parasitic ferromagnetic component appears to reduce as the $\mathrm{Fe}^{2+}$ content of the system is reduced. Field sweep measurements $(5 \mathrm{~K})$ confirm the small FM component. For example, Fig. S3 (ESI $\dagger$ ) for $x=0.5$ shows a small hysteresis consistent with parasitic ferromagnetism, which is superimposed on a large field-dependent signal. Extrapolation of the high-field regions to $H=0$ indicate a FM component of $c a .0 .08 \mu_{\mathrm{B}}$, too small to be detected in the NPD data. The high temperature paramagnetic region of $\mathrm{Fe}_{0.75} \mathrm{Co}_{0.25} \mathrm{Sb}_{2} \mathrm{O}_{4}$ is dominated by a sudden drop in magnetisation at $c a .125 \mathrm{~K}$, which corresponds to the Verwey transition ${ }^{21}$ in the very small
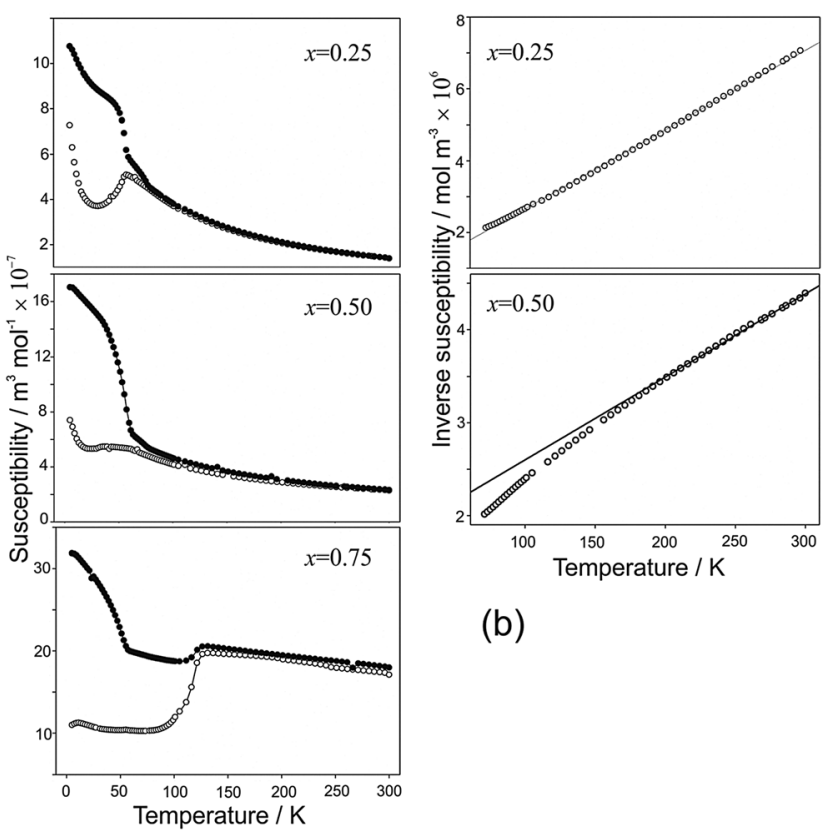

(b)

Fig. 10 (a) Magnetic susceptibility and (b) inverse susceptibility for $\mathrm{Fe}_{x} \mathrm{CO}_{1-x} \mathrm{Sb}_{2} \mathrm{O}_{4}$ under $\mathrm{FC}(\bullet)$ and ZFC (O) conditions, 100 Oe applied field.

$\mathrm{Fe}_{3} \mathrm{O}_{4}$ impurity identified in the NPD data. In addition to the ferromagnetic upturn at $T_{\mathrm{N}}$, both $\mathrm{Fe}_{0.50} \mathrm{Co}_{0.50} \mathrm{Sb}_{2} \mathrm{O}_{4}$ and $\mathrm{Fe}_{0.25} \mathrm{Co}_{0.75} \mathrm{Sb}_{2} \mathrm{O}_{4}$ show a small deviation between $\mathrm{FC}$ and ZFC susceptibilities at temperatures higher than $T_{\mathrm{N}}$ (e.g. $\left.\mathrm{Fe}_{0.25} \mathrm{Co}_{0.75} \mathrm{Sb}_{2} \mathrm{O}_{4}, 59 \mathrm{~K}<T<77 \mathrm{~K}\right)$. Data for $\mathrm{Mn}_{x} \mathrm{Co}_{1-x} \mathrm{Sb}_{2} \mathrm{O}_{4}$ also revealed a canted antiferromagnetic structure with the parasitic ferromagnetism smaller than the $\mathbf{M}^{\prime}=$ Fe series and reducing as $x$ increases; for example, sweep measurements at $5 \mathrm{~K}$ provide a saturated moment of $\sim 0.03 \mu_{\mathrm{B}}$ for $x=1.0$. Samples for $x=0.2 ; 0.4 ; 0.5$ show a magnetic transition between $70 \mathrm{~K}$ and $80 \mathrm{~K}$ but the main transition is observed at lower temperatures $(22-60 \mathrm{~K})$ for these samples, as well as for $x=0.6$. This effect is clearly revealed in the inverse susceptibility data (Fig. 11). The low temperature magnetic features for both series suggest that samples may suffer from a degree of inhomogeneity which results in parts of the sample having higher Néel temperatures. This almost certainly would relate to the $\mathrm{Fe} / \mathrm{Co}$ and $\mathrm{Mn} / \mathrm{Co}$ distributions. In addition, the symmetry of the magnetic model, corresponding to $\Gamma_{5}$ and $\Gamma_{10}$ irreducible representations, is consistent with more than one second-order phase transition.

Apart from the magnetite-containing sample, $\mathrm{Fe}_{0.75} \mathrm{Co}_{0.25} \mathrm{Sb}_{2} \mathrm{O}_{4}$, the high temperature paramagnetic region obeyed the Curie-Weiss law reasonably well as indicated in the plots of inverse susceptibility against temperature (Fig. 10 and 11). However, magnetic deviations are clearly seen for $\mathrm{Fe}_{0.50} \mathrm{Co}_{0.50} \mathrm{Sb}_{2} \mathrm{O}_{4}$ below $150 \mathrm{~K}$. The moments calculated using the linear regions are compared with spin-only values in Fig. 12 and additional details are found in Table 5. As expected, the $\mathrm{Mn}^{2+}$ moment in $\mathrm{MnSb}_{2} \mathrm{O}_{4}$ is in very good agreement with the spin-only value whereas the moment for $\mathrm{Co}^{2+}$ in $\mathrm{CoSb}_{2} \mathrm{O}_{4}$ is substantially higher than that from the electron spin because of the high orbital contributions for the orbitally degenerate 


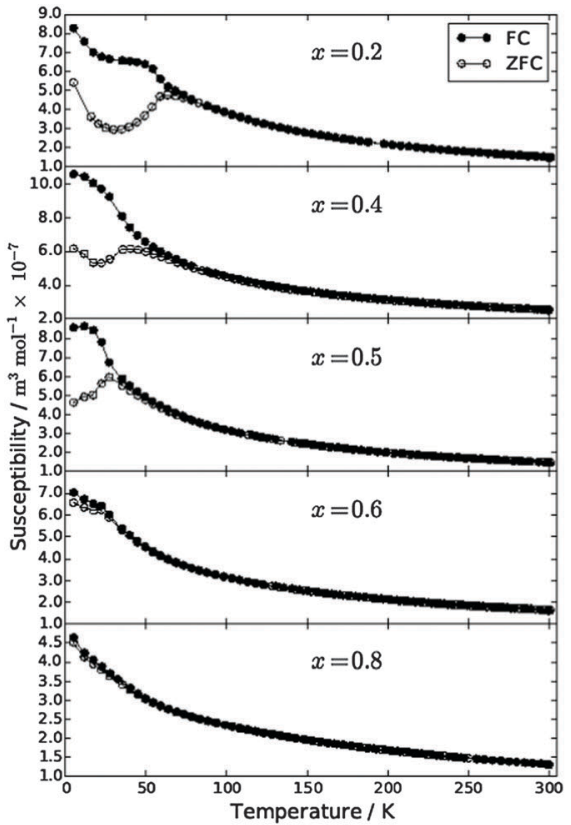

(a)

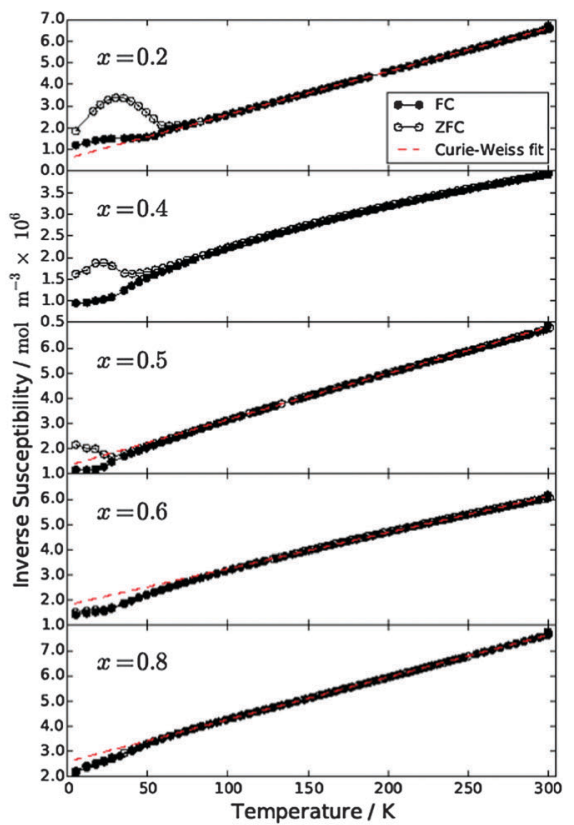

(b)

Fig. 11 (a) Magnetic susceptibility and (b) inverse susceptibility for $\mathrm{Mn}_{x} \mathrm{CO}_{1-x} \mathrm{Sb}_{2} \mathrm{O}_{4}$ under FC (-) and ZFC (O) conditions, 500 Oe applied field.

${ }^{4} \mathrm{~T}_{1 \mathrm{~g}}$ ground state for high spin octahedral $\mathrm{Co}^{2+}$. However, in the absence of additional magnetic interactions we would expect a linear variation of the magnetic moment with composition, i.e. $x$. This is not the case and moments towards the middle of the composition ranges are higher than expected. This is particularly pronounced for $\mathrm{Fe}_{0.50} \mathrm{Co}_{0.50} \mathrm{Sb}_{2} \mathrm{O}_{4}$ with a moment of $8.45 \mu_{\mathrm{B}},(200-300 \mathrm{~K}$, ZFC data). Despite the small divergence between ZFC and FC susceptibilities, the FC measurements returned a similar moment of $8.00 \mu_{\mathrm{B}}$. Although this sample shows curvature of the plot of inverse susceptibility against temperature at lower temperatures, we believe that the deviations of the moments from those expected are real and are probably indicative of some ferromagnetic cluster formation

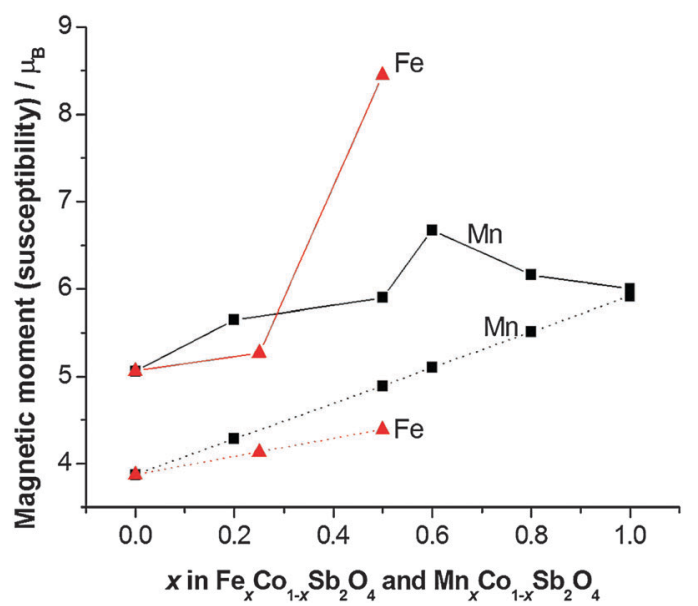

Fig. 12 Effective magnetic moment ( $\mu_{\text {eff, }}$ solid lines) compared with the spin-only magnetic moment ( $\mu_{\text {so }}$, dotted lines) for $\mathrm{Mn}_{x} \mathrm{Co}_{1-x} \mathrm{Sb}_{2} \mathrm{O}_{4}$ and $\mathrm{Fe}_{x} \mathrm{CO}_{1-x} \mathrm{Sb}_{2} \mathrm{O}_{4}$.
Table 5 Magnetic susceptibility data for $\mathrm{Mn}_{x} \mathrm{CO}_{1-x} \mathrm{Sb}_{2} \mathrm{O}_{4}$ and $\mathrm{Fe}_{x} \mathrm{CO}_{1-x} \mathrm{Sb}_{2} \mathrm{O}_{4}$ ( $\mu_{\mathrm{so}}$ corresponds to the spin-only moment; $\theta$ is the Weiss constant)

\begin{tabular}{llllll}
\hline & $x$ & $T_{\mathrm{N}}$ & $\mu_{\text {eff }} / \mu_{\mathrm{B}}{ }^{b}$ & $\mu_{\mathrm{so}} / \mu_{\mathrm{B}}$ & $\theta^{c}$ \\
\hline $\mathrm{Mn}_{x} \mathrm{Co}_{1-x} \mathrm{Sb}_{2} \mathrm{O}_{4}$ & 0.0 & 79 (ref. 11) & 5.06 & 3.87 & +3 \\
& 0.2 & 60 & 5.65 & 4.28 & -31 \\
& 0.4 & 45 & - & 4.69 & - \\
& 0.5 & 27 & 5.90 & 4.89 & -73 \\
& 0.6 & 22 & 6.67 & 5.10 & -126 \\
& 0.8 & $-^{a}$ & 6.16 & 5.51 & -154 \\
& 1.0 & 55 (ref. 20) & 6.0 & 5.92 & -190 \\
$\mathrm{Fe}_{x} \mathrm{Co}_{1-x} \mathrm{Sb}_{2} \mathrm{O}_{4}$ & 0.0 & 79 (ref. 11) & 5.06 & 3.87 & +3 \\
& 0.25 & 57 & 5.27 & 4.13 & -12 \\
& 0.50 & 61 & 8.45 & 4.39 & -191 \\
& 0.75 & 55 & - & 4.64 & - \\
& 1.0 & 45 (ref. 12) & - & 4.90 & -
\end{tabular}

${ }^{a}$ No clear transition from susceptibility data. ${ }^{b}$ Estimated error $\pm 0.08 \mu_{\mathrm{B}}$. ${ }^{c}$ Estimated error $\pm 4 \mathrm{~K}$.

extending to temperatures significantly above the Néel temperature. It is pertinent to note that this sample has the lowest moment determined by NPD, and overall there is a remarkable decrease in the ordered moment towards the centre of the composition ranges for both series (Fig. 8). It therefore seems likely that the magnetic anomalies have a common explanation. The low moments from NPD were attributed to incomplete magnetic order originating from possible short range $\mathrm{Fe} / \mathrm{Co}$ and $\mathrm{Mn} / \mathrm{Co}$ order within the chains of octahedra. A random cation distribution will obviously result in the existence of some chains of type - $\mathrm{Co}-\mathrm{Co}-\mathrm{Co}-$. If such clusters display significant internal FM exchange (as for the C-type order in $\mathrm{CoSb}_{2} \mathrm{O}_{4}$ ) that extends above the Néel temperature or local dipole-dipole interactions along chains, a higher than expected paramagnetic moment would result. Similar effects 
have been observed for other systems, e.g. $\mathrm{LaSr}_{2} \mathrm{CoMnO}_{6} \mu_{\mathrm{eff}}=$ 13.79 $\mu_{\mathrm{B}}{ }^{22}$ and $\mathrm{La}_{1.2} \mathrm{Sr}_{0.8} \mathrm{MnO}_{4.27} \mu_{\mathrm{B}}=8.46 \mu_{\mathrm{B}}{ }^{23}$ However, the negative Weiss constant, e.g. $\theta=-191(3) \mathrm{K}$ for $\mathrm{Fe}_{0.5} \mathrm{Co}_{0.5} \mathrm{Sb}_{2} \mathrm{O}_{4}$ indicates that the overall exchange remains antiferromagnetic. Table 5 shows that for both series the Weiss constant $(\theta)$ becomes more negative as the substitution level $(x)$ increases. Where the low temperature order is predominantly A-type, $-\theta>T_{\mathrm{N}}$, which is normal for antiferromagnetic order when the mean field of each magnetic sublattice is not determined only by the other sublattice. However, for samples with high Co concentrations, we see that $-\theta<T_{\mathrm{N}}$, which is unusual for antiferromagnetic materials; this may be attributed to dominant FM exchange between nearest-neighbour intrachain cations for the C-type ordered structure for $T>T_{\mathrm{N}}$, and the high orbital contribution to the $\mathrm{Co}^{2+}$ moment, which is not included in the basic Curie-Weiss law derivation. As expected, $\theta$ becomes more negative as $x$ increases owing to the increasingly strong AFM intrachain interactions. $T_{\mathrm{N}}$, which marks 3-D order, does not simply follow this trend and is more dependent on the interchain exchange.

\section{Conclusions}

$\mathrm{Mn}_{x} \mathrm{Co}_{1-x} \mathrm{Sb}_{2} \mathrm{O}_{4}$ and $\mathrm{Fe}_{x} \mathrm{Co}_{1-x} \mathrm{Sb}_{2} \mathrm{O}_{4}$ have been synthesised successfully for $0 \leq x \leq 1$. The variation in unit cell size generally reflects the ionic radii of the cations $\left(\mathrm{Mn}^{2+}>\mathrm{Fe}^{2+}>\right.$ $\mathrm{Co}^{2+}$ ) but for $\mathrm{Fe}_{x} \mathrm{Co}_{1-x} \mathrm{Sb}_{2} \mathrm{O}_{4}$ the $c$ parameter surprisingly undergoes a small contraction as $x$ increases. Magnetic susceptibility data show a canted AFM structure for all compounds, although the ferromagnetic component decreases with $x$ in both series. Broad (or possibly two) transitions are observed for many of the samples, which may be attributed to slight sample inhomogeneity of the transition metal ion distribution. NPD data reveal the magnetic structure consists of a transposition of the endmember magnetic structures $\left(\mathrm{A}_{x}\right.$ and $\left.\mathrm{C}_{z}\right)$ which is highly tuneable with $x$. The transition from C-type $(x=0.00)$ to A-type $(x=1.00)$ occurs over a range of $x$ values and occurs via a gradual rotation of the moments from $\pm[001]$ to $\pm[100]$. The observed magnetic moments (from NPD) are significantly lower than expected except for the end-members of the series due to a fully ordered structure not being attained. This is attributed to composition inhomogeneity and the delicate energy balance that exists between the two ordered configurations.

\section{Acknowledgements}

We thank EPSRC for financial support of this research (EP/L014114/1 and EP/P505410/1) and EPSRC, EU and PSI for the provision of NPD facilities. We acknowledge the assistance of Dr Emma Suard, Dr Vladimir Pomjakushin and Dr Winfried Kockelmann in collecting the NPD data. The X-ray diffractometers used in this research were obtained through Birmingham Science City: Creating and Characterising Next Generation
Advanced Materials (West Midlands Centre for Advanced Materials Project 1), with support from Advantage West Midlands (AWM) and part funded by the European Regional Development Fund (ERDF). Requests for additional information/ data should be made to the corresponding author. Data associated with the results shown in this paper are accessible from the University of Birmingham archive: http://epapers.bham.ac.uk/2082/.

\section{References}

1 J. A. Gonzalo, D. E. Cox and G. Shirane, Phys. Rev., 1966, $147,415$.

2 F. Varret, P. Imbert, A. Gerard and F. Hartmann-Boutron, Solid State Commun., 1968, 6, 889.

3 R. Chater, J. R. Gavarri and A. W. Hewat, J. Solid State Chem., 1985, 60, 78.

4 G. Tammann, Z. Anorg. Allg. Chem., 1925, 149, 21.

5 E. Koyama, I. Nakai and K. Nagashima, Nippon Kagaku Kaishi, 1979, 6, 793.

6 J. R. Gavarri, G. Calvarin and B. Chardon, J. Solid State Chem., 1983, 47, 132.

7 H. T. Witteveen, Solid State Commun., 1971, 9, 1971.

8 S. Ståhl, Ark. Kem. Min. Geol., 1943, 17B, 1.

9 M. T. Atanasova, A. M. Strydom, C. J. H. Schutte, L. C. Prinsloo and W. W. Focke, J. Mater. Sci., 2014, 49, 3497.

10 J. R. Gavarri and A. W. Hewat, J. Solid State Chem., 1983, 49, 14 .

11 B. P. de Laune and C. Greaves, J. Solid State Chem., 2012, 187, 225.

12 M. J. Whitaker, R. D. Bayliss, F. J. Berry and C. Greaves, J. Mater. Chem., 2011, 21, 14523.

13 A. M. Abakumov, M. G. Rozova, E. V. Antipov, J. Hadermann, G. Van Tendeloo, M. V. Lobanov, M. Greenblatt, M. Croft, E. V. Tsiper, A. Llobet, K. A. Lokshin and Y. S. Zhao, Chem. Mater., 2005, 17, 1123.

14 H. Abe, K. Yoshii and H. Kitazawa, Phys. Status Solidi A, 2002, 189, 429.

15 H. M. Rietveld, J. Appl. Crystallogr., 1969, 2, 65.

16 A. C. Larson and R. B. Von Dreele, General Structure Analysis System (GSAS), Los Alamos National Laboratory Report LAUR 86-748, 2000.

17 B. H. Toby, J. Appl. Crystallogr., 2001, 34, 210.

18 R. D. Shannon, Acta Crystallogr., Sect. A: Cryst. Phys., Diffr., Theor. Gen. Crystallogr., 1976, 32, 751.

19 G. Gorodetsky, M. Sayar and S. Shtrikman, Mater. Res. Bull., 1970, 5, 253.

20 H. Fjellvag and A. Kjekshus, Acta Chem. Scand., Ser. A, 1985, 39, 389.

21 E. J. W. Verwey and P. W. Haayman, Physica, 1941, 8, 979.

22 H. El Shinawi, A. Bertha, J. Hadermann, B. Santos, J. F. Marco, F. J. Berry and C. Greaves, J. Solid State Chem., 2010, 183, 1347.

23 R. K. Li and C. Greaves, J. Solid State Chem., 2000, 153, 34. 